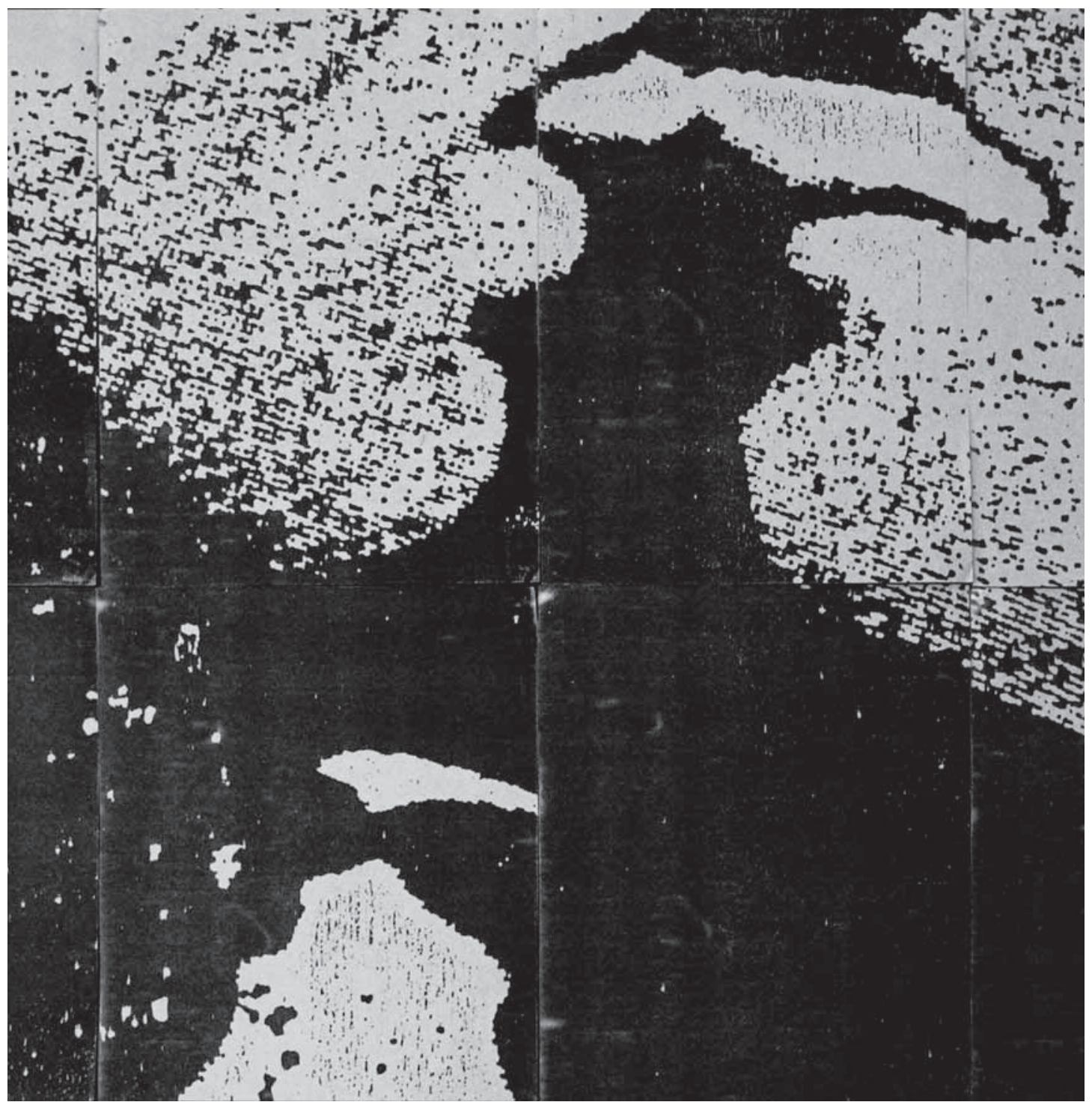




\section{Relato de pesquisa: da similaridade na montagem à tela em movimento.}

palavras-chave: vídeo-instalação, montagem, cinefagia, imagem-emersiva.

keywords: video Installation, film editing, cinefagia, emerging-Image.

Hudinilson Jr. 1980-1984, painel xerográfico.

* Universidade Federal do Rio de Janeiro (UFRJ).
A similaridade é uma força tão fundamental na linguagem que está presente mesmo na linguagem de imagens do cinema. É o que mostram sequências de Outubro (1929), de Eisenstein, apesar do cineasta declarar que seu princípio de montagem é o conflito. A videoinstalação CinemObjeto (2012), realizada como parte dessa pesquisa, investiga o uso da montagem para além da gramática interna do filme, considerando os elementos que circunscrevem o cinema, tanto material e tecnicamente quanto em termos de formas discursivas. A montagem aqui não é entre duas imagens, mas entre imagem e tela em movimento. Esse procedimento, através da "exterioridade da linguagem", produz "imagens emersivas”. Estreitando relações entre teoria e prática, videoinstalação e filosofia, esta pesquisa em progresso explora potências da linguagem audiovisual.

The similarity is present in the foundation of the language, even of the language of images, such as film. Although Eisenstein said that his film editing's principle was the conflict, similarity can be seen in sequences of October (1929). I shall discuss it through the video installation CinemObjeto (2012), performed as part of the theoretical and practical research reported here. The video installation researches the use of film editing beyond its internal grammar, taking into account the factors that limit the film, either material and technically as in terms of discursive forms. The edition here is not between two images, but between image and screen in motion. This procedure, using "external language" produces "emerging images". Strengthening relationships between theory and practice, video installation and philosophy, this ongoing research explores the possibilities of audiovisual and reflects about their achievements. 
Em Outubro (1929), Eisenstein monta o general diante da porta do Palácio com a cauda do pavão se abrindo. Com a junção desses fragmentos, o diretor quer significar a vaidade do militar seduzido pelo poder. O que resta, obtuso, não obstante dotado de significação, é o fato de o pavão girar varrendo graficamente o quadro do centro para a esquerda, e a porta alta e ornamentada do gabinete do poder, por onde o general entra, abrir-se, no fragmento seguinte, num movimento graficamente similar (Fig. 1). A relação proposta entre coisas tão díspares como a vaidade e o pavão (apesar de "vaidoso como um pavão" ter se tornado uma metáfora consagrada) é de similaridade simbólica, mas também existe similaridade gráfica, na dimensão sensível ou, como queria o cineasta, "emocional-fisiológica". As imagens, nessa e em outras sequências de Outubro, como veremos, fazem o mesmo que o conceito: aproximam elementos diferentes por semelhança. Com isso pretendo mostrar que a similaridade é um fundamento presente mesmo na linguagem por imagens criada pelo revolucionário cineasta, cujo princípio declarado de montagem era o conflito ${ }^{1}$.

Além de ter como unidade mínima o fragmento, e não o plano, uma segunda decomposição é operada no interior do próprio fragmento. Em Eisenstein, nem a unidade mínima é indivisível. O cineasta decompõe os fragmentos em parâmetros internos de luminosidade, contraste, duração, cor, volume, ângulo etc. Os parâmetros dizem respeito às características plástico-materiais da imagem, o que Barthes chamaria de "o seu sentido obtuso"2. Mas, quais são as relações internas entre os fragmentos dentro de um parâmetro eleito? Aos 29 minutos do filme, a imagem do militar de braços cruzados é montada com a imagem da miniatura de Napoleão de braços cruzados, enquadrada do mesmo modo (Fig. 2). A escala e o volume são similares.

Relato de pesquisa: da similaridade na montagem à tela em movimento

1. 1. A arte, na concepção dialética de Eisenstein, é conflito: "A lógica da forma orgânica versus a lógica racional produz, em colisão, a dialética da forma artística". EISENSTEIN, Sergei.

Dramaturgia da forma do filme. In: A forma do filme. Rio de Janeiro: Ed. Jorge Zahar, 2002, p. 50.

2. Nas imagens há um sentido óbvio, literal, e outro obtuso, opaco, que emana da própria imagem. Cf. BARTHES, Roland. 0 óbvio e o obtuso. Rio de Janeiro: Ed Nova Fronteira, 1990.

Figura 1.




Na mesma sequência, o fragmento em que aparecem taças e vasos de cristal enfileirados é montado com o fragmento em que aparecem soldadinhos de chumbo enfileirados de modo similar, ambos destacados contra o fundo negro (Fig. 3). As coisas são signos, representações de ideias, quase palavras; não coisas reais registradas por uma câmera.

Figuras 2 e 3.

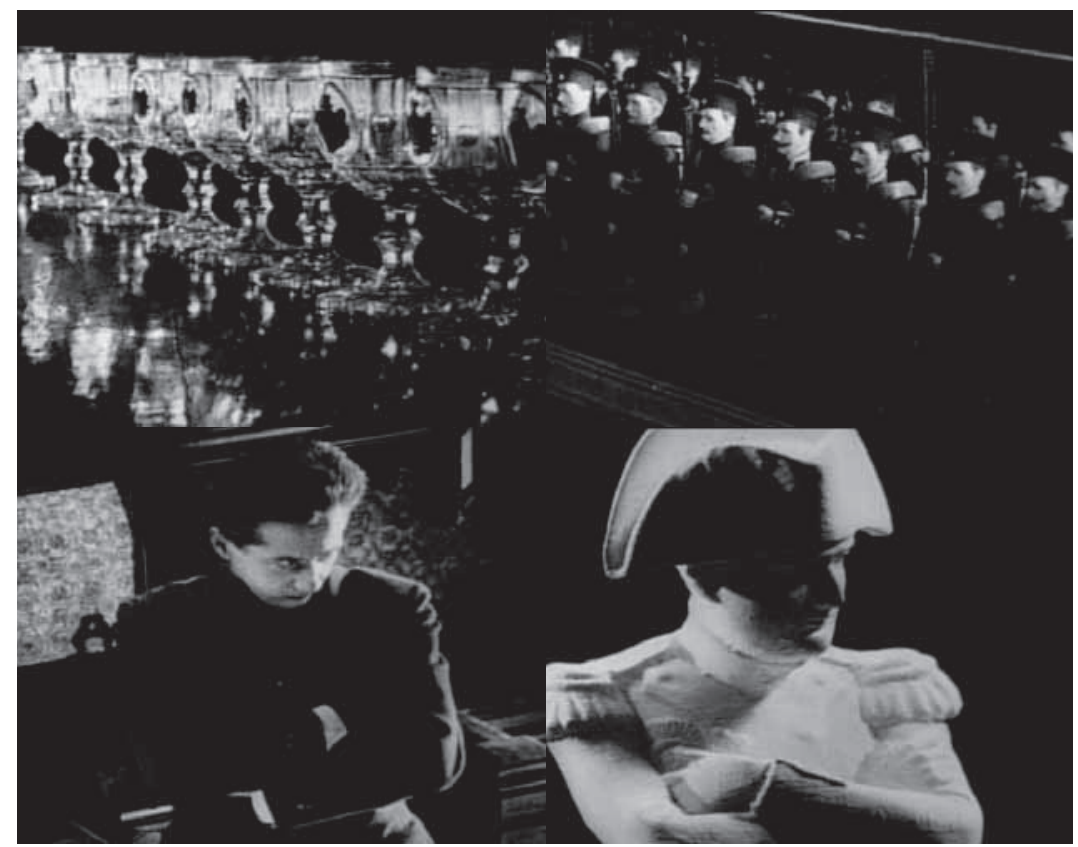

Para expressar ideias por imagens, Eisenstein relacionou parâmetros que deveriam emanar das próprias imagens. Embora os frag-

3. JAKOBSON, Roman. Dois aspectos da linguagem e dois tipos de afasia. In: Linguística

e Comunicação. São Paulo:

Cultrix, s/data, p. 49-50.

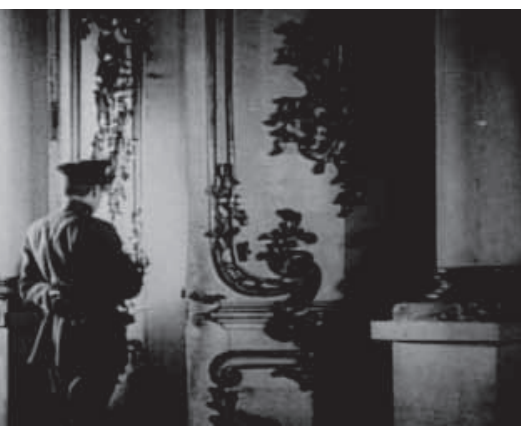
mentos se choquem (a cauda do pavão e o palácio do governo não estão no mesmo contexto), o cineasta cria uma relação de similaridade visual entre eles. Como nas metáforas, nos ideogramas e nos conceitos, a similaridade, aqui, é o modo de operar da linguagem.

Os dois tipos fundamentais de arranjo da linguagem e de atividade mental, para Roman Jakobson, são a associação por similaridade ou seleção e a associação por contexto ou combinação. Todo o pensamento corresponde, segundo o linguista, a um desses dois tipos de arranjo $^{3}$. O conceito de interpretante, de C. S. Peirce, por sua vez, define a relação que se estabelece entre um signo e aquele outro signo no qual, necessariamente, o primeiro será interpretado. A relação entre os dois, no caso da montagem intelectual eisensteiniana, corresponde ao eixo da similaridade, responsável pela metáfora ${ }^{4}$. 
De volta ao primeiro exemplo: o que um pavão tem a ver com negociações na cúpula do poder? Na medida em que estão lado a lado numa sequência fílmica, o pavão e a porta do palácio pela qual os militares entram combinam-se numa relação de contiguidade; mas, simultaneamente, há um segundo eixo, operando por critérios de similaridade. Segundo esse critério, uma imagem poderia substituir a outra, pois elas se equivalem.

Aos 31 minutos do filme, forças contrarrevolucionárias tentam retomar o poder em nome de Deus e da Pátria. Eisenstein tem de construir, nas imagens, o sentido de que a religião é o ópio do povo. Ele põe estátuas e bonecos de deuses de várias religiões, do cristianismo ao paganismo e a religiões orientais, montados lado a lado, e equipara as figuras por parâmetros visuais: o enquadramento, a luminosidade, o grafismo. Elas se relacionam seja pela similaridade, como um sinônimo visual, seja pelo antônimo, estabelecido sobre um fundo comum.

Nos fotogramas abaixo, por exemplo, os pelos da sobrancelha e da barba do ídolo pagão contrastam, pela textura, com a brancura lisa da porcelana do Buda, cujo rosto arredondado, por sua vez, contrasta, segundo parâmetros geométricos, com os traços retos do ídolo africano (Fig. 4).

\section{FERNANDO GERHEIM}

Relato de pesquisa: da similaridade na montagem à tela em movimento

4. PEIRCE, C. S. Semiótica. São Paulo: Perspectiva, 2010, p. 74.

Figura 4.



Eisenstein compreende a montagem como um princípio não só do cinema, mas de todas as artes e do próprio pensamento. E o processo relacional que se cria entre um fragmento e outro, na sua montagem, é marcado, como vimos, pela relação de semelhança. Para a teoria semiótica de Peirce, além de estar presente nos signos icônicos, a semelhança marca os dois tipos de raciocínio que caracterizam os signos simbólicos.

A fórmula do ícone é: o signo tem propriedades semelhantes às do objeto que ele significa. Enquanto que, na dimensão simbólica, as duas formas de raciocínio (dedução e indução) também operam por 
5. EISENSTEIN, Sergei. Palavra e Imagem. In: $\mathbf{0}$ sentido do filme. Rio de Janeiro: Ed Jorge Zahar, 1990, p. 14.

6. WITTGENSTEIN, L. Investigações Filosóficas. São Paulo: Editora Nova Cultural, 1999 (Coleção Os Pensadores), p. 28.

7. Vídeo-instalação de Fernando Gerheim, apresentada em janeiro/ fevereiro de 2012, na exposição Coletiva Quântica 3.0, na galeria Artur Fidalgo, no Rio de Janeiro. Da exposição também fez parte, de Gerheim, o trabalho $A$ arte do pensamento ou a ponta solta do aqui e agora. Valorizando o processo de criação à obra pronta, a exposição foi se transformando durante o tempo. Ela foi realizada junto com Franklin Cassaro, que apresentou as obras Eu não vou explicar esse trabalho e Átomos. Registro online: http://www.youtube.com/ watch?v=luL3bZjAlww. mas terá que reduzi-lo ao que ele tem de comum com os outros particulares para chegar a uma ideia geral, privilegiando do mesmo modo a semelhança.

"Estamos acostumados a fazer, quase que automaticamente, uma síntese dedutiva definida e óbvia quando quaisquer objetos isolados são colocados à nossa frente lado a lado" ${ }^{5}$. Diz Eisenstein, relacionando a montagem a um processo lógico.

$\mathrm{Na}$ montagem eisensteiniana, portanto, a similaridade entre parâmetros opera como fundamento. A questão, agora, é: como lidar com essa formatação pela linguagem que acabamos de surpreender até mesmo no revolucionário cineasta russo?

2

O objetivo deste artigo, daqui em diante, será explorar a possibilidade de usar a montagem para além da gramática interna do filme, incorporando a dimensão material-discursiva que o circunscreve. Se em Eisenstein as ideias são uma forma, em CinemObjeto elas são, na expressão de Wittgenstein, o uso que se faz de tal forma ${ }^{6}$. Ao invés de um fragmento ao lado do outro, a montagem em CinemObjeto (2012) ${ }^{7}$ é entre a imagem e a tela. O quadro, que circunscreve materialmente o cinema, tem sua inserção na linguagem reelaborada. A tela adota a forma do pictograma de travessia de pedestres, que remete ao espaço público urbano das ruas, deixando o convencional retângulo. Os pictogramas são espelhados, refletindo as imagens transformadas nas demais paredes do espaço. O uso da tela como imagem desfaz a própria tela estática. Não há mais tela, a imagem pode estar em qualquer parte. O pictograma que simboliza movimento em movimento tem esse duplo sentido. A montagem entre as imagens e a tela em movimento mesclam linguagens: é cinescultura e videoinstalação.

Os pictogramas de acrílico espelhado, suspensos a uma pequena distância da parede por uma linha amarrada a um prego, balançam levemente, projetando seus reflexos agigantados e em movimento aleatório nas paredes opostas. Enquanto a imagem de cinema move-se na tela fixa, em CinemObjeto, a própria tela, duplicada em imagem, está em movimento (Figs. 5 a 8). As imagens dos cidadãos atravessando a rua, refletidas de volta com o contorno dos signos urbanos, ora parecem 
correr e deslizar, ora saltitar e pular. O signo universal de travessia de pedestres é o conceito fixo, enquanto a multidão de pedestres atravessando a rua é o fluxo dos fenômenos. Em CinemObjeto, o signo universal está em movimento.

\section{FERNANDO GERHEIM}

Relato de pesquisa: da similaridade na montagem à tela em movimento

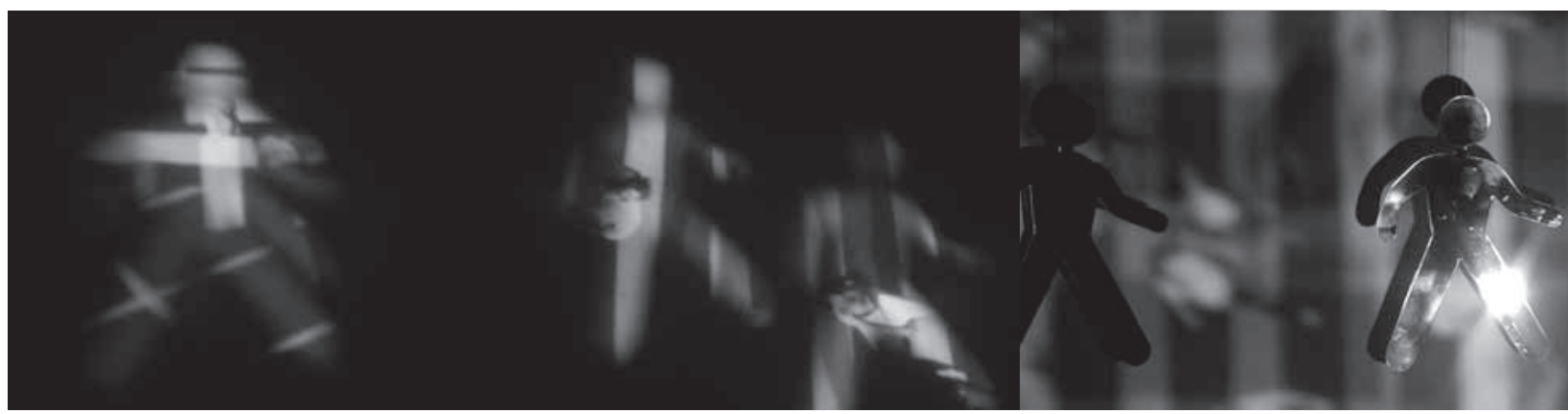

Com a passagem da janela convencional ao pictograma espelhado, ao invés de receptáculo neutro, a tela passa a também projetar. Com a alteração do formato e a mobilidade, ela se torna uma tela particular.

A relação entre pedestres atravessando a rua e o signo icônico do design urbano que o significa é, ao mesmo tempo, entre o universal e o particular e entre a unidade e o múltiplo. Uma imagem está dentro da outra. A relação é, afinal, entre o conceito, enquanto abstração que cria tipos gerais, e a percepção, para a qual tudo é particular. Qual a relação entre os dois? O conceito é o signo que reúne a diversidade empírica. $\mathrm{O}$ particular está, supostamente, dentro do geral. Esta é uma relação que discute a própria linguagem, qualquer linguagem.

A imagem dos pedestres atravessando a rua é literalmente superposta ao pictograma que a nomeia numa linguagem universalista, e a relação entre os dois não se resolve em nenhuma síntese dedutiva e óbvia criada na mente do espectador, como na montagem eisensteiniana. O particular e o geral não são fragmentos que se fundem por similaridade numa metáfora visual. Eles são um cinecaligrama em que a imagem tem a forma do seu significado, e o significado contém a imagem particular.

Nessa segunda projeção, os reflexos luminosos dos pictogramas, ampliados e móveis, ocupando o espaço com leveza, parecem querer se sobrepor uns aos outros. E, nesses cinessignos, a imagem dos pedestres atravessando a rua dentro do pictograma de pedestres atravessando a rua, ao invés de se unificar, se multiplica. Além de correr, pular e se perseguir mutuamente, ao se sobrepor, as imagens criam
Figuras 5, 6 e 7. 
ARS terceiras imagens imprevistas, não presentes em nenhuma das duas isoano 12 ladamente (Fig 8). E também se dividem entre as paredes separadas do

n. 23 espaço. Se a tela virou imagem, ela agora é a própria arquitetura, produzindo quartas e quintas imagens (Fig. 9). A montagem aqui é porosa à contingência, não está inteiramente predefinida.

\section{3}

O método é incorporar os próprios elementos materiais que circunscrevem uma determinada linguagem. Ela deixa assim de privilegiar a similaridade, e de apagar diferenças com sua pseudouniversalidade. A imagem do signo universal de travessia de pedestres com a imagem da multidão particular de pedestres dentro cria uma relação caligramática entre as imagens. Mas ao contrário do caligrama tradicional, em que as palavras formam a imagem do seu sentido, aqui, é a imagem que toma a forma do seu sentido. Essa nova relação de montagem, caligramática, tem ressonância dentro da própria forma do cinema. Aqui, a apropriação do digital não leva à realidade virtual, nem a imagens imersivas, mas, antes, a imagens emersivas. O pictograma de travessia de pedestre que serve de tela aos pedestres reais gravados em vídeo atravessando a

Figura 8. rua é uma espécie de caligrama em que o particular e o geral dependem um do outro. A imagem que irrompe como descontinuidade neste cinecaligrama é a suposta forma do cinema.

Um segundo conjunto de imagens torna mais nítida a convergência entre a unidade conceitual e a dispersão perceptual: o jorro luminoso do rio corrente faz com que o contorno do pictograma perca a definição. Os riscos de luz do rio e o fluxo da multidão se correspondem de algum modo na multiplicidade. Na montagem entre as imagens e a tela, o fluido e o unitário convivem. As imagens da correnteza são mostradas ou em planos isolados ou em fusões, criando texturas hipnóticas Figura 9. e imagens abstratas. As imagens da velocidade da luz, sem forma nem limite, são montadas com os contornos bem delineados dos pictogramas, que, assim, perdem o seu contorno preciso.

Acionar o aparato técnico, por mais simples que pareça, atinge o osso da linguagem. O material que circunscreve a produção da imagem não está mais do seu lado de fora. Usado, ele é também exposto como significação. A tela, agora, é imagem. A linguagem não cabe mais no linguístico. Em sua dimensão material, ela ultrapassa a comunicação de conteúdos e a abstração conceitual. CinemObjeto deixa a tela mental 
para entrar no corpo do cinema, na sua exterioridade. $\mathrm{O}$ cinema passa a ser o "uso" que se faz de uma forma, como diz o aforismo de Wittgenstein. O deslocamento do sentido para o uso faz da linguagem uma "forma de vida”. Transcrevo o fragmento 43 de seu Investigações Filosóficas: "Pode-se, para uma grande classe de casos de utilização da palavra ‘significação' - se não para todos os casos de sua utilização -, explicá-la assim: a significação de uma palavra é seu uso na linguagem”.

Ao considerar a fala no contexto cotidiano pragmático, Wittgenstein rompe com a teoria referencial do sentido. Estendendo o que ele diz à imagem em movimento, temos que a significação do cinema é uma "forma de vida”, que está muito além de um sentido linguístico, ou, melhor, cinelinguístico. Se Wittgenstein às vezes pode fazer parecer que a forma de vida é homogênea - "O aceito, o dado - poder-se-ia dizer - são formas de vida" ${ }^{-}$, a ideia da linguagem como uso, proposta aqui, pelo contrário, é necessariamente a da emergência do que não é dado nem aceito. A linguagem como o seu uso a partir daquilo que a circunscreve, tanto técnica e materialmente quanto discursivamente, transforma em elemento de significação o que era exterior a essa linguagem. E o seu uso não é usual.

$\mathrm{O}$ conceito de imagem técnica, aquela cujo processo de produção é, em maior ou menor grau, automatizado, seria impensável sem esse olhar materialista. Para Philippe Dubois, o cinema é uma imagem técnica de terceira ordem, que acrescenta às imagens técnicas anteriores (a câmera obscura e a fotografia) a projeção e a impressão de movimento ${ }^{10}$. CinemObjeto isola uma dessas características materiais do cinema - a projeção -, dispositivo constitucional e invisível que se transforma em material significante. $O$ trabalho retira, assim, o cinema do âmbito da consciência, e o leva para o de seus usos. A tela e o quadro, que o inscreviam e o codificavam, uma vez utilizados, eles próprios, como elementos de significação, tornam o cinema um corpo sensível.

CinemObjeto afirma a imagem como uma presença pré-gramatical, indicial e contingente. O "monstro hipnótico" ou "o subfilme mítico e infantil" "1 , como Pasolini definia o cinema, aqui deglutidos pelo vídeo, reaparecem na conexão física com o espaço, ocupado pelo movimento aleatório e reiterativo do dispositivo transparente e não-tecnológico. Em CinemObjeto, a imagem não é a da consciência, nem mesmo a da memória ou a do sonho, mas a da linguagem inseparável do dispositivo que a produz. Seu único fundamento é a sua própria projeção, que ele incorpora para saltar na matéria de sua própria invenção (Figs 10 e 11).

\section{FERNANDO GERHEIM}

Relato de pesquisa: da similaridade na montagem à tela em movimento

8. WITTGENSTEIN, L. Op. cit., p. 28.

9. Idem, pág. 203.

10. DUBOIS, Phillip. Máquinas de imagens: uma questão de linha geral. In: Cinema Vídeo, Godard. São Paulo: CosacNaify, 2004.

11. PASOLINI, Pier Paolo.

0 cinema de poesia. In: Empirismo hereje. Lisboa: Assírio e Alvim, 1982, p. 141.

Figuras 10 e 11.
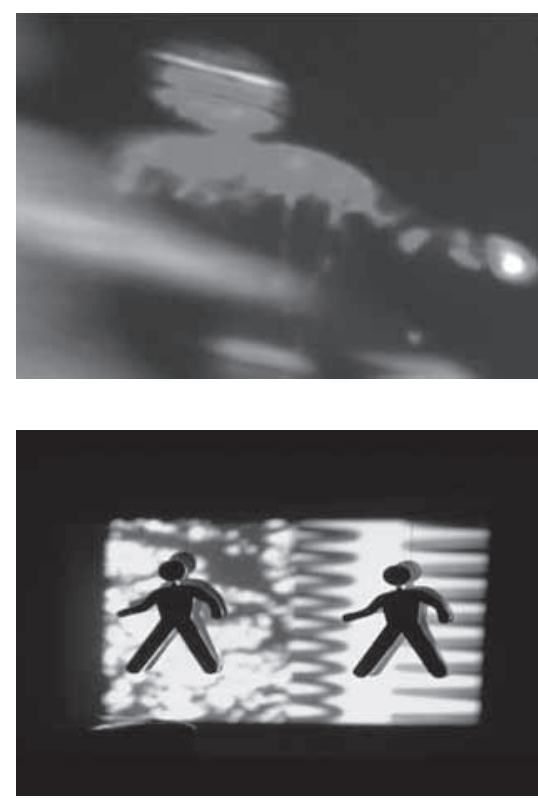


\section{ARS Bibliografia complementar}

ano 12

n. 23 DERRIDA, Jacques. A Farmácia de Platão. São Paulo: Iluminuras, 1997. GERHEIM, Fernando. Linguagens inventadas - palavra imagem objeto: formas de contágio. Rio de Janeiro: Ed. Jorge Zahar, 2008.

KRAUSS, Rosalind. A escultura no campo ampliado. In: Revista Gávea, Rio de Janeiro, n. 1, dezembro de 1984.

SAUSSURE, Ferdinand. Curso de Linguística Geral. São Paulo: Cultrix, s/ data.

Fernando Gerheim é Professor da Escola de Comunicação da Universidade Federal do Rio de Janeiro, Professor do Programa de Pós-Graduação em Artes da Cena e Professor Colaborador do Programa de Pós-Graduação em Artes Visuais da UFRJ. Autor de Linguagens inventadas - palavra imagem objeto: formas de contágio (2008), de Signofobia (2012), e de vários vídeos e videoinstalações. Esta pesquisa foi desenvolvida com apoio da FAPERJ. 